\title{
Pulmonology
}

\section{Clinical Phenotype "Obesity-Asthma" as One of the Main Problems of Personalized Pulmonology}

\author{
Ludmila V. Tribuntceva, $\mathrm{PhD}^{1}$; Yanina S. Shkatova ${ }^{1}$; Sergey N. Avdeev, PhD, ScD²; \\ Andrey V. Budnevsky, $\mathrm{PhD}, \mathrm{ScD}^{1}$; Evgeniy S. Ovsyannikov, $\mathrm{PhD}^{{ }^{*}}$ \\ ${ }^{1}$ Voronezh State Medical University named after N.N. Burdenko, Voronezh, Russia \\ ${ }^{2}$ I. M. Sechenov First Moscow State Medical Univesity, Moscow, Russia
}

\begin{abstract}
Background: Asthma is a heterogeneous disease comprising different phenotypes. One of the most common asthma phenotypes is the obesity-asthma phenotype, since obesity affects over a third of the world's population today. It is important to continue investigating possible underlying mechanisms of the interaction between asthma and obesity. The purpose of this study was to evaluate levels of leptin, adiponectin, neuropeptide Y (NPY), total oxidative damage (TOD), and total antioxidant status (TAS) in patients with asthma and different body weight (BW), and to analyze their association with spirometry parameters.

Materials and Methods: The study included 27 men and 86 women diagnosed with moderate asthma (mean age of $57.81 \pm 13.05$ years). During the study, all asthma patients were divided into 3 groups. Group 1 included 37 patients with normal BW, Group 2 included 38 overweight patients, and Group 3 included 38 patients with obesity. We analyzed complaints, anamnesis data, objective status data, and laboratory (blood levels of NPY, adiponectin, leptin, total antioxidant status, and total oxidative damage) and instrumental data (spirometry). Two questionnaires were used: Asthma Quality of Life Questionnaire (AQLQ) and Asthma Control Test (ACT).

Results: The leptin level was significantly higher in Group 3 compared to Groups 1 and $2(P=0.000)$. The NPY level was significantly lower in Group 1 compared to Groups 2 and $3(P=0.000)$. The TAS value was significantly higher in Group 1 compared to Groups 2 and $3(P=0.000)$ and the TOD value in Group 1 was significantly lower than in Group $3(P=0.038)$. The leptin level positively correlated with BMI and waist circumference, and had an inverse correlation with FEV 1 and vital capacity (VC). The adiponectin level had a positive correlation with the Tiffno index, $\mathrm{FEF}_{50}$, and peak expiratory flow (PEF). The NPY level had an inverse correlation with $\mathrm{VC}, \mathrm{FEV}_{1}, \mathrm{FEF}_{25}, \mathrm{FVC}$, Tiffno index, $\mathrm{FEF}_{50}$, and PEF.

Conclusion: The severity of the clinical course of moderate asthma in obese patients is associated with different factors, including oxidative stress and levels of leptin, adiponectin and NPY. (International Journal of Biomedicine. 2019;9(2):117-120.)
\end{abstract}

Key Words: asthma $\bullet$ body weight $\bullet$ oxidative stress $\bullet$ leptin $\bullet$ adiponectin $\bullet$ neuropeptide $\mathrm{Y}$

\section{Abbreviations}

BMI, body mass index; BW, body weight; $\mathbf{F E V}$, forced expiratory volume in $1 \mathrm{sec} ; \mathbf{F E F}$, forced expiratory flow; FVC, forced vital capacity; NPY, neuropeptide Y; OS, oxidative stress; PEF, peak expiratory flow; TAS, total antioxidant status; TOD, total oxidative damage; VC, vital capacity; WC, waist circumference.

\section{Introduction}

According to the Global Initiative for Asthma (GINA), asthma is a serious disease, which affects around 300 million people worldwide. One of the most important factors for

*Corresponding author: Evgeniy S. Ovsyannikov, PhD Voronezh State Medical University named after N.N. Burdenko. Voronezh, Russia. E-mail: ovses@yandex.ru. clinicians is that asthma is a heterogeneous disease. It is the heterogeneity of the disease that dictates the need for the most individualized treatment. ${ }^{(1,2)}$ The heterogeneity of both clinical manifestations of asthma and response to therapy is considered nowadays. ${ }^{(3,4)}$ We distinguish many asthma phenotypes, and even subphenotypes, based on those factors. ${ }^{(5-7)}$ Currently, the search for special pathological and molecular features of asthma phenotypes continues, which can become the basis for the development of individual therapy. One of 
the most common asthma phenotypes is the obesity-asthma phenotype, since obesity affects over a third of the world's population today. It is also estimated that the prevalence of obesity will continue to grow and by 2030 , about $38 \%$ of the world's adult population will be overweight and $20 \%$ will be obese.$^{\left({ }^{8}\right)}$ Considering all of the above, it is important to continue investigating possible underlying mechanisms of the interaction between asthma and obesity. Adiponectin, leptin, OS, and NPY remain relevant in this field of study.

The purpose of this study was to evaluate levels of leptin, adiponectin, NPY, TOD, and TAS in patients with asthma and different BW, and to analyze their association with spirometry parameters.

\section{Materials and Methods}

The study included 27 men and 86 women diagnosed with moderate asthma aged from 18 to 75 years (mean age of $57.81 \pm 13.05$ years).

The study was approved by the Ethics Committee of Voronezh State Medical University named after N.N. Burdenko. (Protocol № 1 from February 21, 2018). Written informed consent was obtained from each patient.

Exclusion criteria were patients' refusal to participate in this study; asthma exacerbation; acute and chronic neurological, psychiatric and endocrinological disorders at the time of examination; chronic diseases in the acute stage; severe and decompensated diseases of liver and kidneys; severe and decompensated cardiovascular diseases (acute period of myocardial infarction, unstable angina, transient ischemic attack, intracerebral hemorrhage, acute heart failure, etc.); cancer; multiple organ failure of different genesis; cancer; pregnancy and lactation; severe infectious diseases.

The asthma diagnosis was based on the integral assessment of symptoms, medical history, health status, and spirometry values according to the Global Strategy for Asthma Management and Prevention. ${ }^{(9)}$

We analyzed complaints, anamnesis data, objective status data, and laboratory and instrumental data (spirometry with a 400-mg salbutamol test), and we measured levels of NPY, adiponectin, leptin, total antioxidant status, and total oxidative damage.

The levels of leptin and adiponectin were measured using the appropriate reagent kits for quantitative determination of leptin and adiponectin in serum. The determination of TOD was carried out with use of a reagent kit to determine the degree of TOD to biological molecules (PerOx (TOS) (Oxidative Capacity)). We determined the overall antioxidant status by using reagents for determining TAS (ImAnOx (TAS) (Antioxidative Capacity)). NPY levels were measured with a reagent kit for NPY determination in serum.

Two questionnaires were used in this study: Asthma Quality of Life Questionnaire (AQLQ) and Asthma Control Test (ACT). All patients received standard asthma therapy.

All data was evaluated with STATGRAPHICS Plus 5.1. Baseline characteristics were summarized as frequencies and percentages for categorical variables and as mean $\pm \mathrm{SD}$ for continuous variables. Student's unpaired t-test was used to compare two groups for data with normal distribution. Group comparisons with respect to categorical variables are performed using the Chi-square test. Multiple comparisons were performed with one-way ANOVA and Tukey's HSD Post-hoc Test. Pearson's correlation coefficient (r) was used to determine the strength of the relationship between the two continuous variables. A probability value of $\mathrm{P}<0.05$ was considered statistically significant.

\section{Results}

During the study, all asthma patients were divided into 3 groups. Group 1 included 37 patients with normal BW, Group 2 included 38 overweight patients, and Group 3 included 38 patients with obesity. The three groups did not differ with regard to age and sex (Table 1).

Table 1.

General characteristics of patients

\begin{tabular}{|c|c|c|c|}
\hline Parameters & $\underset{(n=37)}{\text { Group } 1}$ & $\underset{(n=38)}{\text { Group } 2}$ & $\begin{array}{c}\text { Group } 3 \\
(n=38)\end{array}$ \\
\hline \multirow{3}{*}{$\begin{array}{l}\text { Women, n (\%) } \\
\text { Men, n }(\%)\end{array}$} & $12(32.4)$ & $8(21.1)$ & $7(18.4)$ \\
\hline & $25(67.6)$ & $30(78.9)$ & $31(81.6)$ \\
\hline & \multicolumn{3}{|c|}{$P>0.05$} \\
\hline \multirow[t]{2}{*}{ Age. years } & $54.43 \pm 16.93$ & $58.68 \pm 9.94$ & $60.21 \pm 10.96$ \\
\hline & \multicolumn{3}{|c|}{$\mathrm{F}=0.0535 ; P=0.9480$} \\
\hline \multirow{4}{*}{$\begin{array}{l}\text { Higher education, n (\%) } \\
\text { Specialized secondary } \\
\text { education, } \mathrm{n}(\%) \\
\text { Secondary education, } \\
\text { n (\%) }\end{array}$} & $25(67.6)$ & $16(42.1)$ & $9(23.7)$ \\
\hline & $8(21.6)$ & $14(36.8)$ & $22(57.9)$ \\
\hline & & & \\
\hline & \multicolumn{3}{|c|}{$\chi^{2}=15.875 ; P=0.003$} \\
\hline \multirow{3}{*}{$\begin{array}{l}\text { Married, n (\%) } \\
\text { Single, n (\%) }\end{array}$} & $13(35.1)$ & $6(15.8)$ & $22(57.9)$ \\
\hline & $24(64.9)$ & $32(84.2)$ & $16(42.1)$ \\
\hline & \multicolumn{3}{|c|}{$\chi^{2}=14.602 ; P=0.0007$} \\
\hline
\end{tabular}

Laboratory test results are presented in Table 2. The leptin level was significantly higher in Group 3 compared to Groups 1 and $2(P=0.0000)$. No statistically significant differences in adiponectin levels were found in the studied groups. The NPY level was significantly lower in Group 1 compared to Groups 2 and $3(P=0.0000)$. The TAS value was significantly higher in Group 1 compared to Groups 2 and 3 $(P=0.0000)$. The value of total oxidative damage in Group 1 was significantly lower than in Group $3(P=0.0382)$.

Correlation coefficients between laboratory and spirometry data are presented in Table 3 . The leptin level positively correlated with BMI $\mathrm{r}=0.56 ; P<0.05)$ and $\mathrm{WC}$ $(\mathrm{r}=0.42 ; P<0.05)$, and had an inverse correlation with $\mathrm{FEV}_{1}$ $(\mathrm{r}=-0.28 ; P<0.05)$ and $\mathrm{VC}(\mathrm{r}=-0.29 ; \mathrm{P}<0.05)$. The adiponectin level had a positive correlation with the Tiffno index $(\mathrm{r}=0.51$; $P<0.05), \mathrm{FEF}_{50}(\mathrm{r}=0.37 ; P<0.05)$, and PEF $\left.\mathrm{r}=0.33 ; P<0.05\right)$. The NPY level had an inverse correlation with VC $(\mathrm{r}=-0.75$; $P<0.05), \mathrm{FEV}_{1}(\mathrm{r}=-0.57 ; P<0.05), \mathrm{FEF}_{25}(\mathrm{r}=-0.53 ; P<0.05)$, FVC ( $\mathrm{r}=-0.45 ; P<0.05)$, Tiffno index $(\mathrm{r}=-0.32 ; P<0.05), \mathrm{FEF}_{50}$ $(\mathrm{r}=-0.41 ; P<0.05)$, and $\mathrm{PEF}(\mathrm{r}=-0.38 ; P<0.05)$. 
Table 2.

Laboratory test results in the studied groups

\begin{tabular}{|l|c|c|c|c|}
\hline \multicolumn{1}{|c|}{ Parameters } & Group 1 & Group 2 & Group 3 & Statistics \\
\hline Leptin, $\mathrm{ng} / \mathrm{ml}$ & $13.01 \pm 1.97$ & $11.32 \pm 1.99$ & $22.36 \pm 1.97$ & $\begin{array}{l}\mathrm{F}=343.0272 P=0.0000 \\
P_{1-2}=0.0010 P_{1-3}=0.0000 \\
P_{2-3}=0.0000\end{array}$ \\
\hline NPY, ng/ml & $0.31 \pm 0.02$ & $0.48 \pm 0.02$ & $1.19 \pm 0.25$ & $\begin{array}{l}\mathrm{F}=386.0549 P=0.0000 \\
P_{1-2}=0.0000 P_{1-3}=0.0000 \\
P_{2-3}=0.0000\end{array}$ \\
\hline TAS, $\mu \mathrm{mol} / 1$ & $535.78 \pm 64.35$ & $277.59 \pm 63.49$ & $287.96 \pm 63.49$ & $\begin{array}{l}\mathrm{F}=196.0883 P_{1-2}=0.0000 \\
P_{2-3}^{1-3}=0.7588\end{array} P_{1-3}=0.0000$ \\
\hline TOD, $\mu \mathrm{mol} / 1$ & $877.70 \pm 623.33$ & $1177.75 \pm 1022.51$ & $1454.69 \pm 1257.72$ & $\begin{array}{l}\mathrm{F}=3.0876 P=0.0496 \\
P_{1-2}=0.4026 \\
P_{2-3}=0.4553\end{array}$ \\
\hline Adiponectin, $\mu \mathrm{g} / \mathrm{ml}$ & $23.66 \pm 11.03$ & $23.40 \pm 11.29$ & $23.70 \pm 10.25$ & $\mathrm{~F}=0.0085 P=0.9915$ \\
\hline
\end{tabular}

Table 3.

Correlation coefficients between laboratory and spirometry data

\begin{tabular}{|l|c|c|c|c|c|c|c|c|c|c|}
\hline Parameters & FEV1 & FVC & VC & Tiffno & FEF 25\% & FEF 50\% & FEF 75\% & PEF & BMI & WC \\
\hline Adiponectin & 0.04 & -0.08 & -0.07 & $0.51^{*}$ & 0.05 & $0.37 *$ & $0.24^{*}$ & $0.33^{*}$ & -0.06 & 0.12 \\
\hline Leptin & $-0.28^{*}$ & -0.25 & $-0.29^{*}$ & -0.18 & -0.11 & -0.23 & $-0.15^{*}$ & $-0.15^{*}$ & $0.56^{*}$ & $0.42^{*}$ \\
\hline NPY & $-0.57^{*}$ & $-0.45^{*}$ & $-0.75^{*}$ & $-0.32^{*}$ & $-0.53 *$ & $-0.41^{*}$ & -0.18 & $-0.38^{*}$ & 0.20 & 0.05 \\
\hline TAS & -0.03 & $0.43^{*}$ & $0.36^{*}$ & $-0.40^{*}$ & 0.00 & -0.33 & $-0.42^{*}$ & $-0.36^{*}$ & $-0.32^{*}$ & -0.15 \\
\hline TOD & 0.23 & 0.22 & 0.07 & $-0.43^{*}$ & 0.18 & -0.08 & 0.04 & -0.01 & $0.50^{*}$ & $0.48^{*}$ \\
\hline
\end{tabular}

$*$-P-value $<0.05$.

\section{Discussion}

Our study showed that levels of leptin, NPY and TOD were significantly higher and the TAS level was significantly lower in asthmatic patients with obesity compared with asthmatic patients who were overweight or had normal body weight, indicating inflammatory activity. According to GINA (2019), obesity is a state of chronic low-grade inflammation with increased adipocyte-driven proinflammatory activity. Adipose tissue cells secrete adipokines, and the role of such adipokines as leptin and adiponectin in asthma continues to be investigated. Studies show that there is a correlation between BW and levels of leptin, even though there is also a gender difference: women with the same BMI as men have higher concentrations of leptin. ${ }^{(10)}$ Leptin is a proinflammatory cytokine and might be one of the contributing factors to the higher prevalence of asthma in obese patients. It stimulates release of NO, IL-6 and IL-8 and TNF- $\alpha \cdot{ }^{(6)}$ At the same time, an experimental study on mice found that administration of TNF- $\alpha$ led to an increase of leptin levels. ${ }^{(1)}$ Higher levels of leptin are associated with asthma; this association is stronger in women than men, and more pronounced in premenopausal women than in postmenopausal women. ${ }^{(1)}$

On the other hand, adiponectin plays an opposite role, inhibiting inflammation. Our study also showed that adiponectin functions as an inhibitor of inflammation in asthma, since it had a positive correlation with spirometry parameters. The data about the association between asthma and adiponectin are contradictory. Some studies suggested that low levels of adiponectin are associated with greater odds for asthma in women, ${ }^{(12,13)}$ while others deny any correlation at all. ${ }^{(14,15)}$ Other studies report that higher levels of adiponectin correlate with milder asthma, but only in women, while in men this association is the opposite: asthma that required more frequent use of medication was associated with higher adiponectin levels. ${ }^{(16,17)}$ There was also a study that analyzed serum adiponectin levels and expression of adiponectin mRNA in abdominal adipose tissue in obese patients. Patients with obesity and asthma had lower adiponectin mRNA expression than obese patients without asthma, but levels of serum adiponectin did not differ significantly in these groups. ${ }^{(18)}$ There is also information about decreased levels of serum adiponectin, but only during exacerbations in asthma patients. (19) These data invoke a thought that a decreased level of adiponectin might be not the predictor, but the consequence of asthma's clinical course.

OS plays an important role in asthma. According to the latest research, biomarkers of OS are higher in patients with obesity and correlate with BMI, ${ }^{(20)}$ and at the same time antioxidant defense biomarkers have an inverse correlation 
with BW. ${ }^{(21)}$ In our study, we observed the same association in asthmatic patients with different BW.

There are limited studies on the association between NPY and asthma. A few studies report that certain genotypes of NPY are associated with asthma. ${ }^{(22,23)}$ Y1 receptors of NPY play an important role in allergic inflammation of respiratory airways. (24) One study also reports that during asthma exacerbations, levels of NPY increase. ${ }^{(25)}$ In our study, levels of NPY were significantly higher in obese and overweight asthmatics and had an inverse correlation with spirometry parameters, indicating a negative effect on the clinical course of asthma.

In conclusion, it can be said, that the severity of the clinical course of asthma in obese patients is associated with different factors, including OS and levels of leptin, adiponectin and NPY. Exact mechanisms remain unclear. Also in this study, we included only patients with moderate asthma, did not analyze gender differences, and did not differentiate between women of premenopausal and postmenopausal age. Further research is required.

\section{Competing Interests}

The authors declare that they have no competing interests.

\section{References}

1. Budnevsky AV, Tribuntceva LV, Kozhevnikova SA, Ovsyannikov ES. Impact of metabolic syndrome components on asthma control and life quality of patients. International Journal of Biomedicine. 2018;8(1):33-36. doi: 10.21103/ article8(1)_OA4.

2. Budnevsky AV, Malysh EY, Ovsyannikov ES, Drobysheva ES. [Asthma and metabolic syndrome: Clinical and pathogenetic relationships]. Ter Arkh. 2015;87(10):110-114. doi: 10.17116/terarkh20158710110-114. [Article in Russian]. 3. Tsvetikova LN, Budnevsky AV, Ovsyannikov ES, Kudashova EA. [Melatonin: Possibilities for use in the treatment of asthma]. Ter Arkh. 2017;89(3):112-115. doi: 10.17116/terarkh2017893112-115. [Article in Russian].

4. Provotorov VM, Budnevsky AV, Filatova YI. [Clinical manifestations of asthma during combination therapy using ceruloplasmin]. Ter Arkh. 2016;88(3):36-39. doi: 10.17116/ terarkh201688336-39. [Article in Russian].

5. Hirose M, Horiguchi T. Asthma phenotypes. J Gen Fam Med. 2017;18(5):189-194. doi: 10.1002/jgf2.7.

6. Matsusaka M, Fukunaga K, Kabata H, Izuhara K, Asano K, Betsuyaku T. Subphenotypes of type 2 severe asthma in adults. J Allergy Clin Immunol Pract. 2018;6(1):274-276.e2. doi: 10.1016/j.jaip.2017.06.015.

7. Zacharias J, Ishmael FT, Henao M, Rael EL. Identification of Sub-Phenotypes of Eosinophilic Asthma: Eosinophilic Asthma Is Not Always Allergic Asthma. The Journal of Allergy and Clinical Immunology. 2017;139(2):AB170. doi: 10.1016/j.jaci.2016.12.557.

8. Hruby A, Hu FB.The Epidemiology of Obesity: A Big Picture. Pharmacoeconomics. 2015;33(7):673-89. doi: 10.1007/ s40273-014-0243-x.

9. Global strategy for asthma management and prevention (GINA, 2017 REPORT). Available from: file://C:/Users/Admin/ Downloads/wmsGINA-2017-main-report-final_V2\%20(1).pdf 10. Ruhl CE, Everhart JE. Leptin concentrations in the United
States: relations with demographic and anthropometric measures. Am J Clin Nutr. 2001;74(3):295-301.doi: 10.1093/ajen/74.3.295. 11. Vuolteenaho K, Koskinen A, Kukkonen M, Nieminen R, Päivärinta U, Moilanen T, et al. Leptin enhances synthesis of proinflammatory mediators in human osteoarthritic cartilage-mediator role of NO in leptin-induced PGE2, IL-6, and IL-8 production. Mediators Inflamm. 2009;2009:345838. doi: $10.1155 / 2009 / 345838$.

12. Sood A, Ford ES, Camargo CA Jr. Association between leptin and asthma in adults. Thorax. 2006;61(4):300-5. doi: 10.1136/thx.2004.031468.

13. Sood A, Cui X, Qualls C, Beckett WS, Gross MD, Steffes $\mathrm{MW}$, et al. Association between asthma and serum adiponectin concentration in women. Thorax. 2008;63(10):877-82. doi: 10.1136/thx.2007.090803.

14. Nagel G, Koenig W, Rapp K, Wabitsch M, Zoellner I, Weiland SK. Associations of adipokines with asthma, rhinoconjunctivitis, and eczema in German schoolchildren. Pediatr Allergy Immunol. 2009;20(1):81-8. doi: 10.1111/j.1399-3038.2008.00740.x.

15. Jartti T, Saarikoski L, Jartti L, Lisinen I, Jula A, Huupponen R, et al. Obesity, adipokines and asthma. Allergy. 2009;64(5):770-7. doi: 10.1111/j.1398-9995.2008.01872.x.

16. Sutherland TJ, Sears MR, McLachlan CR, Poulton R, Hancox RJ. Leptin, adiponectin, and asthma: findings from a population-based cohort study. Ann Allergy Asthma Immunol. 2009;103(2):101-7. doi: 10.1016/S1081-1206(10)60161-5.

17. Sood A, Dominic E, Qualls C, Steffes MW, Thyagarajan B, Smith LJ, et al. Serum Adiponectin is Associated with Adverse Outcomes of Asthma in Men but Not in Women. Front Pharmacol. 2011;2:55. doi:10.3389/fphar.2011.00055.

18. Tsaroucha A, Daniil Z, Malli F, Georgoulias P, Minas M, Kostikas K, et al. Leptin, adiponectin, and ghrelin levels in female patients with asthma during stable and exacerbation periods. J Asthma.2013;50(2):188-97.doi:10.3109/02770903.2012.747101. 19. Sideleva O, Suratt BT, Black KE, Tharp WG, Pratley RE, Forgione P, et al. Obesity and asthma: an inflammatory disease of adipose tissue not the airway. Am J Respir Crit Care Med. 2012;186(7):598-605. doi: 10.1164/rccm.201203-0573OC.

20. Pihl E, Zilmer K, Kullisaar T, Kairane C, Mägi A, Zilmer M. Atherogenic inflammatory and oxidative stress markers in relation to overweight values in male former athletes. Int $\mathrm{J}$ Obes (Lond). 2006;30(1):141-6. doi: 10.1038/sj.ijo.0803068. 21. Chrysohoou C, Panagiotakos DB, Pitsavos C, Skoumas I, Papademetriou L, Economou M, et al.The implication of obesity on total antioxidant capacity in apparently healthy men and women: the ATTICA study. Nutr Metab Cardiovasc Dis. 2007;17(8):590-7. doi: 10.1016/j.numecd.2006.05.007.

22. Lu Y, Andiappan AK, Lee B, Ho R, Lim TK, Kuan WS, et al. Neuropeptide Y associated with asthma in young adults. Neuropeptides.2016;59:117-121.doi:10.1016/j.npep.2016.07.003. 23. Jaakkola U, Kakko T, Juonala M, Lehtimäki T, Viikari $\mathrm{J}$, Jääskeläinen AE, et al. Neuropeptide Y polymorphism increases the risk for asthma in overweight subjects; protection from atherosclerosis in asthmatic subjects--the cardiovascular risk in young Finns study. Neuropeptides. 2012;46(6):321-8. doi: 10.1016/j.npep.2012.09.005.

24. Macia L, Rao PT, Wheway J, Sierro F, Mackay F, Herzog H. Y1 signalling has a critical role in allergic airway inflammation. Immunol Cell Biol. 2011;89(8):882-8. doi: 10.1038/icb.2011.6. 25. Cardell LO, Uddman R, Edvinsson L. Low plasma concentrations of VIP and elevated levels of other neuropeptides during exacerbations of asthma. Eur Respir J. 1994;7(12):2169-73. 